\title{
POTENSI BAJA KARBON RENDAH SEBAGAI BAHAN BAKU ALTERNATIF PEMBUATAN DODOS (ALAT PANEN BUAH KELAPA SAWIT )
}

\section{THE POTENTIAL OF LOW CARBON STEEL AS ALTERNATIVE RAW MATERIALS FOR MANUFACTURE OF CHISEL (TOOL FOR HARVESTING OIL PALM FRUIT)}

\author{
Winda Sri Jaman, Sri Bimo Pratomo, Mirantie Dwiharsanti, K Nurdin Saleh \\ Balai Besar Logam dan Mesin, Kementerian Perindustrian \\ Jl. Sangkuriang No.12 Bandung 40135 \\ email: windasrijaman@gmail.com
}

\begin{abstract}
Abstrak
Dodos merupakan salah satu jenis alat panen tandan buah segar (TBS) kelapa sawit. Salah satu permasalahan yang dihadapi industri kecil menengah (IKM) sekarang adalah ketersediaan bahan baku. IKM membuat dodos dari skrap baja per (baja karbon medium) yang ketersediaannya terbatas dan kurang berkelanjutan. Saat ini baja karbon medium belum bisa diproduksi di dalam negeri sehingga ketergantungan akan skrap baja karbon medium tinggi. sehingga bahan baku alternatif untuk membuat dodos diperlukan untuk mendukung kebutuhan dalam negeri. Baja karbon rendah merupakan bahan baku alternatif untuk membuat dodos dan mudah didapatkan di pasaran. Untuk memenuhi persyaratan teknis dodos, proses tambahan diperlukan. Metode Pack Karburisasi merupakan metode pengerasan di permukaan yang dapat diaplikasikan pada dodos. Dalam penelitian ini, parameter metoda karburisasi padat yang divariasikan adalah temperatur, waktu penahanan, dan komposisi bahan karburisasi. Kekerasan maksimal didapat pada kondisi temperatur $950^{\circ} \mathrm{C}$, waktu penahanan 30 menit, komposisi arang 50\%+barium karbonat $50 \%$ yang menghasilkan kekerasan $55,49 \pm 3,74$ HRC. Kondisi kekerasan minimal pada kondisi temperatur $900^{\circ} \mathrm{C}$, waktu penahanan 15 menit, komposisi arang batok 70\%+barium karbonat $50 \%$ didapatkan kekerasan 42,63 $\pm 5,29$ HRC.
\end{abstract}

Kata kunci : Dodos, Karburisasi Padat, Pengerasan Permukaan

\begin{abstract}
Chisel is one of the types of oil palm harvesting tool. One of the problems faced by Small and Medium Industries (SME's) is the availability of raw material. SME's made chisel from spring steel scarp (medium carbon steel) with limited and unsustain supply. Medium carbon steel can't yet be produced domestically, so that the dependence on scrap is very high. The alternative raw material to produce the chisel is needed to support domestic demand. Low carbon steel is an alternative material to produce chisel which is widely available in the country. To meet the requirement, additional process is needed. Pack carburizing is one of the methods to increase the hardness of the chisel. In this research, the variation in carburizing parameters was the temperature, hold time, and carburization material composition. The results showed that the maximum hardness was obtained from temperature of $950^{\circ} \mathrm{C}$, holding time of 30 minutes, and charcoal composition of $50 \%+$ barium carbonate of $50 \%$ with hardness $55.49 \pm 3.74$ HRC. The minimum hardness was obtained in temperature $900^{\circ} \mathrm{C}$, holding time 15 minutes, the composition of charcoal batok $70 \%+50 \%$ barium carbonate with hardness $42.63 \pm 5.29$ HRC.
\end{abstract}

Keywords : Chisel, Pack carburizing, Case Hardening

\section{PENDAHULUAN}

Salah satu bidang industri yang termasuk dalam industri prioritas pemerintah Indonesia adalah industri agro, salah satunya adalah industri pertanian. Saat ini petani kelapa sawit mengimpor alat panennya dari luar negeri (Cina dan Malaysia). ${ }^{7,8}$ Alat panen tandan buah segar (TBS) kelapa sawit jenis dodos. Di Indonesia 
pada umumnya dibuat dengan proses tempa dan menggunakan bahan baku baja karbon menengah. Sulitnya bahan baku baja karbon menengah menjadi salah satu alasan dilakukannya penelitian alternatif bahan baku untuk alat panen tandan buah segar (TBS) kelapa sawit jenis dodos. Pemilihan bahan baku alternatif untuk baja karbon rendah sebagai alat panen tandan buah segar (TBS) kelapa sawit jenis dodos dengan alasan murahnya harga bahan baku ini dan ketersediaannya yang berlimpah di Indonesia. Baja Karbon rendah dianggap mempunyai potensi untuk bahan baku alat panen tandan buah segar (TBS) kelapa sawit jenis dodos. Penelitian ini sangat diperlukan untuk membuat produk dodos yang mampu bersaing dengan produk luar negeri sehingga akan berdampak pada berkembangnya industri kecil menengah dalam negeri. ${ }^{7,8}$

Metoda pack carburizing ${ }^{5}$ adalah suatu proses penambahan unsur karbon pada permukaan suatu komponen secara difusi untuk memperbaiki sifat mekaniknya. ${ }^{1,2,3,4}$ Proses ini biasanya dilakukan terhadap baja karbon rendah. Pada penelitian ini baja karbon rendah akan diubah sifat mekanis permukaannya dengan metoda pack carburizing, permukaan logam yang keras dan bagian dalam yg lentur akan dihasilkan dari produk hasil pack carbirizing ini disebabkan karena jumlah karbon pada permukaan baja meningkat, sehingga sifat mekanis dari permukaan baja akan meningkat, sifat ini ni dibutuhkan untuk komponen yang saling bergesekan atau karena fungsinya harus mempunyai kekerasan tertentu dan ulet di bagian dalamnya. Pemilihan metoda pack carburizing dianggap tepat untuk penelitian ini berdasarkan berbagai literatur yang ada.

Kebaruan dari metode pack carburizing adalah modifikasi proses (arang batok dan $\mathrm{BaCO} 3$ dibuat dalam bentuk pasta). Dengan tujuan untuk menghemat media pack carburizing dan dapat menghasilkan kekerasan tertinggi dengan hasil yang tidak jauh berbeda dengan metoda pack carburizing pada umumnya.

\section{METODE PENELITIAN}

\section{Bahan}

Bahan baku baja karbon rendah yang digunakan adalah kelas ST37 yang terdapat banyak di pasaran kemudian dibuat ukuran sampel $100 \mathrm{x}$ $50 \times 2 \mathrm{~mm}$. Pengujian awal dilakukan pada bahan baku untuk memastikan Komposisi dari bahan baku ini adalah baja karbon rendah adalah seperti dapat dilihat pada Tabel.1. Kandungan kadar karbon 0,178\% menunjukkan kadar karbon pada bahan baku ini memasuki kelas baja karbon rendah. Preparasi baja dengan cara membersihkan baja, dengan cara digerinda amplas atau dengan amplas tangan sampai bersih dari pengotor/karat di permukaan baja sehingga proses pack carburizing bisa berlangsung dengan baik.

Tabel.1. Komposisi kimia bahan baku baja karbon rendah

\begin{tabular}{|c|c|c|c|}
\hline Unsur & $\%$ & Unsur & $\%$ \\
\hline $\mathrm{Fe}$ & 98.86 & $\mathrm{Co}$ & 0.001 \\
\hline $\mathrm{C}$ & 0.178 & $\mathrm{Cu}$ & 0.002 \\
\hline $\mathrm{Si}$ & 0.023 & $\mathrm{Nb}$ & 0.005 \\
\hline $\mathrm{Mn}$ & 0.731 & $\mathrm{Sn}$ & 0.003 \\
\hline $\mathrm{P}$ & $<0.002$ & $\mathrm{Ti}$ & 0.001 \\
\hline $\mathrm{S}$ & $<0.002$ & $\mathrm{~V}$ & $<0.002$ \\
\hline $\mathrm{Cr}$ & 0.029 & $\mathrm{~W}$ & $<0.005$ \\
\hline $\mathrm{Mo}$ & $<0.002$ & $\mathrm{Ca}$ & $<0.0003$ \\
\hline $\mathrm{Ni}$ & 0.014 & $\mathrm{~Pb}$ & $<0.001$ \\
\hline $\mathrm{Al}$ & 0.034 & $\mathrm{Zn}$ & 0.003 \\
\hline $\mathrm{B}$ & 0.0005 & & \\
\hline
\end{tabular}

\section{Persiapan Media Pack carburizing}

Media pack carburizing yang digunakan adalah serbuk batok arang dan barium carbonat yang disiapkan dengan variasi komposisi 50\% arang batok $+50 \%$ barium karbonat dan $70 \%$ arang batok+50 \%. Tambahkan air secukupnya kemudian aduk sehingga bentuknya menjadi pasta. Setelah itu logam dioleskan dengan pasta pack carburizing pada bagian yang akan ditajamkan. Masukkan pada kotak stainless steel yang sudah dioelskan pasta arang ke dalam kotak stainless steel. Dimaksudkan untuk kemudahan pemindahan kedalam tungku pemanas dan supaya tidak kotor.

\section{Proses Carburizing}

Pemanasan dilakukan pada suhu mencapai $700^{\circ} \mathrm{C}$ kemudian masukkan baja yang sudah dipreparasi dengan pasta pack carburizing, masukkan ke dalam tungku pemanas kemudian naikkan temperatur untuk variasi $900^{\circ} \mathrm{C}$ dan $950^{\circ} \mathrm{C}$. Variasi suhu sudah tercapai keluarkan baja dari tungku pemanas kemudian celupkan 
dengak cepat kedalam media pengingin (media quench). Bersihkan dari sisa serbuk arang untuk dilakukan pengujian.

Proses tempering tidak dilakukan pada pack carburizing karena tujuan penelitian awal dari proses ini untuk mengetahui kondisi optimum dalam mengeraskan bagian permukaan baja sehingga baja yang dikeraskan akan tahan terhadap keausan.

\section{Pengujian Kekerasan Pada Produk Carburizing}

Pengujian kekerasan dimaksudkan untuk mengetahui ketahanan bahan atau logam terhadap deformasi yaitu deformasi tekan atau indentasi. Pada umumnya pengujian kekerasan bertujuan untuk mengukur tahanan dari bahan atau logam terhadap deformasi plastis. Prinsip pengukurannya adalah dengan memberi gaya tekan melalui sebuah indentor pada permukaan bahan atau logam. Kemudian luas atau dimensi atau diameter dari jejak penekanan/indentasi diukur. Pengujian Rockwel direkomendasikan untuk mengukur mengukur kekerasan permukaan dari bahan yang permukaan logamnya dikeraskan, berdasarkan standard ASTM E 18-05 Ed.2008.

Pengujian kekerasan pada penelitian ini hanya dilakukan di beberapa titik di permukaan yang terkarburisasi saja.

\section{Pengujian Struktur Mikro}

Pengujian Struktur mikro dan SEM bertujuan untuk mengetahui atau pembuktian pada produk hasil pack carburizing permukaan logamnya sudah terlapisi atau belum terlapisi setelah proses pack carburizing, karena dengan penambahan karbon secara difusi akan mengakibatkan penambahan kekerasan pada permukaan logam.

Baja hasil carburizing dipotong memanjang sehingga dihasilkan potongan sampel baja hasil carburizing dan logam dasarnya. Lakukan pembingkaian (mounting) sehingga sampel mudah untuk dipegang. Amplas permukaan sampel yang akan diamati mulai dari amplas grit 80-2000 dengan putaran searah, setiap pergantian amplas sampel carburizing diputar $45^{\circ}$ untuk menghilangkan goresan-goresan halus di semua arah. Setelah itu polishing dengan alumina dan etsa dengan nital 5\% selama 5 detik untuk menimbulkan tekstur struktur mikro. Amati dengan menggunakan mikroskop optik Nikkon pada pembesaran 1001000x pembesaran. Sehingga terlihat jelas terbentuknya lapisan carburizing pada baja (case depth). ${ }^{11}$

\section{HASIL PEMBAHASAN}

Uji kekerasan awal sebelum dilakukan proses pengerjaan pack carburizing dilakukan . Hasil pengujian kekerasan dihasilkan 21,6 HRC. Pengujian kekerasan awal dilakukan dimaksudkan untuk mengetahui perubahan dan kenaikan kekerasan setelah proses pack carburizing. ${ }^{10}$

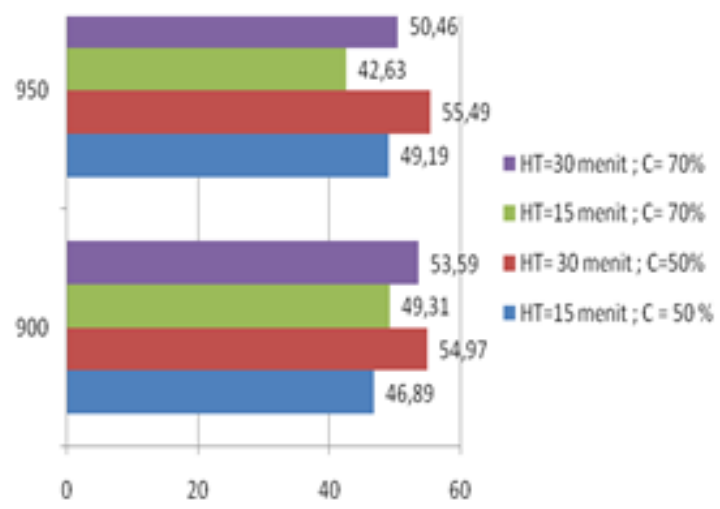

Gambar 1. Gambar pengaruh suhu pemanasan, waktu penahanan (holding time) dan komposisi pack carburizing

\section{Pengaruh Temperatur pada Kekerasan Produk Carburizing}

Kekerasan tertinggi didapat pada kondisi temperatur $950^{\circ} \mathrm{C}$, waktu penahanan 30 menit, komposisi arang 50\%+barium karbonat $50 \%$ didapatkan kekerasan 55,49 HRC $( \pm 3,74)$. Makin tinggi temperatur menyebabkan difusivitas semakin tinggi, karena atom-atom memiliki energi termal yang lebih tinggi dan dengan demikian probabilitas untuk diaktifkan hingga melampaui hambatan energi antara atom juga lebih besar. Karbon akan memasuki rongga-rongga permukaan logam yang lebih banyak dengan berdifusi sehingga memberikan pengaruh kekerasan pada permukaan logam. Gambar 1. Menunjukkan peningkatan terhadap pengujian kekerasan dengan semakin tingginya temperatur pemanasan pada proses pack carburizing.

Kekerasan terendah pada kondisi temperatur $900^{\circ} \mathrm{C}$, waktu penahanan 15 menit, komposisi arang batok $70 \%$ dan barium karbonat $50 \%$ 
didapatkan kekerasan 42,63 HRC $( \pm 5,29)$. Makin rendah temperatur menyebabkan difusivitas semakin rendah, karena atom-atom memiliki energi termal yang lebih rendah dan dengan demikian probabilitas untuk diaktifkan tidak optimum untuk melampaui hambatan energi antara atom juga semakin kecil. Karbon akan memasuki rongga-rongga permukaan logam yang lebih sedikit dengan berdifusi sehingga memberikan pengaruh kekerasan pun akan berkurang pada permukaan logam. Gambar.1. Menunjukkan penurunan terhadap pengujian kekerasan dengan semakin rendahnya temperatur pemanasan pada proses pack carburizing.

\section{Pengaruh Waktu Penahanan (Holding Tim ) terhadap Kekerasan Produk Carburizing}

Baja karbon rendah pada sekitar temperatur austenit mempunyai afinitas terhadap karbon. Bila semakin lama waktu penahanan maka karbon akan mempunyai kesempatan untuk berdifusi ke bagian lebih dalam. Kekerasan permukaan baja karbon rendah juga tergantung pada tebal lapisan dan akan dipengaruhi juga oleh parameter waktu dan temperatur perlakuan panas. Pada Gambar 1. akan menunjukkan semakin lama waktu penahanan maka akan semakin memberikan pengaruh kekerasan yang disebabkan oleh cukupnya waktu karbon untuk berdifusi atau memasuki rongga-ronnga permukaan baja karbon rendah. Jika waktu penahanan lebih sebentar maka tidak akan cukup waktu untuk karbon berdifusi atau memasuki rongga-rongga baja karbon rendah.

\section{Pengaruh Komposisi Media Pack carburizing terhadap Kekerasan Produk Carburizing}

Komposisi yang memberikan pengaruh kekerasan yang tinggi adalah pada komposisi $50 \%$ arang batok $+50 \%$ barium karbonat. Untuk komposisi $70 \%$ arang batok $+50 \%$ barium karbonat terjadi penurunan kekerasan . Seiring dengan menurunya waktu penahanan dan temperatur sintering akan memberikan pengaruh penurunan kekerasan. Komposisi 1:1 sangat direkomendasikan karena akan memberikan kehomogenan hasil kekerasan pada baja karbon rendah.

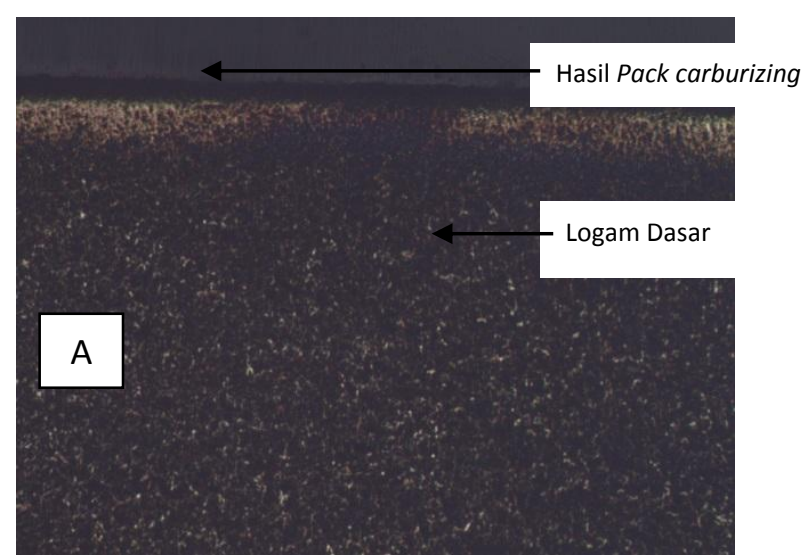

Gambar. 2. A. Hasil pengujian struktur mikro

Pada Gambar 2. A. Hasil pengujian struktur mikro, dapat dilihat bagian yang terkarburisasi dan tidak. Pengujian ini dimaksudkan untuk mengetahui adanya/terbentuknya lapisan karburisasi sebagai pengaruh pengerasan terhadap baja karbon rendah. Pengerasaan ini hanya hanya terjadi pada bagian permukaan logam saja dan tidak sampai ke dalam bagian logam dasar.

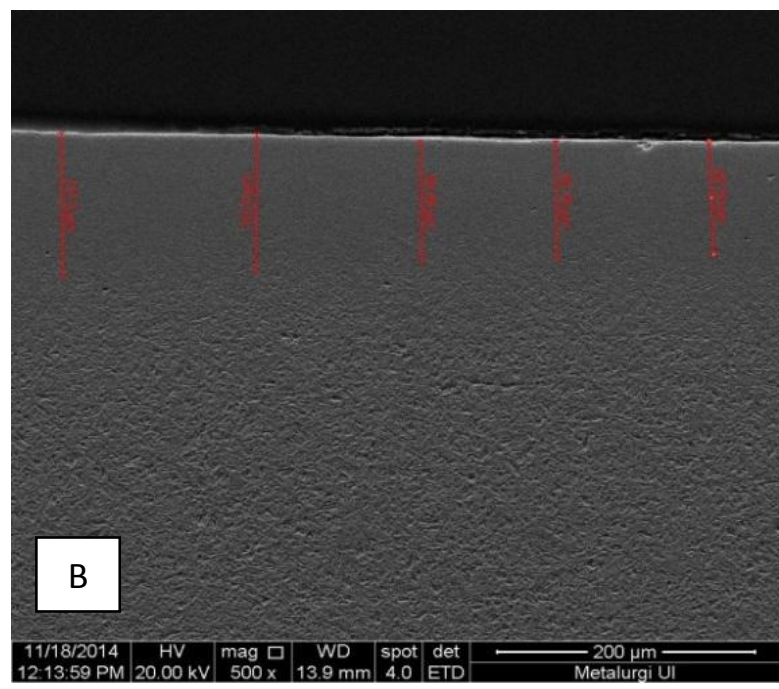

Gambar. 2. B. Hasil pengujian SEM

Pada Gambar 2. B. Hasil pengamatan SEM menunjukkan ketebalan lapisan karburisasi (seperti garis putih) terendah $96.75 \mu \mathrm{m}$ dan yang tertinggi 117.2 $\mu \mathrm{m}$. Ketebalan ini mencukupi untuk bagian ujung dodos, sehingga dihasilkan kekerasan tertinggi 55,49 HRC. Tetapi untuk lebih meningkatkan kualitas kekerasan dan umur pakai dodos diperlukan ketebalan lebih tinggi lagi. Untuk itu perlu ditingkatkan ketebalan lapisan karburisasinya dengan menambahkan waktu penahanan proses karburisasi. 
Hal ini juga disebabkan oleh komposisi media carburizing yaitu arang batok sebagai sumber yang menghasilkan karbon dan barium karbonat sebagai aktivator atau energizer pada proses pack carburizing. Komposisi arang 50\% arang batok $+50 \%$ barium karbonat adalah media yang optimum yang menghasilkan ketebalan lapisan tertinggi $117.2 \mu \mathrm{m}$ dibandingkan dengan media carburizing dengan komposisi $70 \%$ arang batok $+50 \%$ barium karbonat yang menghasilkan ketebalan lapisan terendah $96.75 \mu \mathrm{m}$.

\section{KESIMPULAN}

Parameter metoda karburisasi padat yang divariasikan adalah temperatur, waktu penahanan, komposisi bahan pada metoda karburisasi padat. Kekerasan tertinggi didapat pada kondisi temperatur $950^{\circ} \mathrm{C}$, waktu penahanan 30 menit, komposisi arang $50 \%$ +barium karbonat $50 \%$ didapatkan kekerasan 55,49 HRC $( \pm 3,74)$. Kekerasan terendah pada kondisi temperatur $900^{\circ} \mathrm{C}$, waktu penahanan 15 menit, komposisi arang batok $70 \%$ +barium karbonat $50 \%$ didapatkan kekerasan 42,63 HRC $( \pm 5,29)$.

Pengujian struktur mikro menunjukkan perbedaan antara material dasar dan permukaan yang dikaburisasi, sedangkan hasil uji SEM diketahui ketebalan lapisan karburisasi sekitar 96.75-117.2 $\mu \mathrm{m}$. Ketebalan ini mencukupi untuk bagian ujung dodos.

Untuk keperluan khusus seperti dodos/alat panen kelapa sawit, diperlukan material baja yang memiliki sifat-sifat khusus juga antara lain bagian permukaan kontak memiliki kekerasan $>45$ HRC serta tahan aus dan bagian dalam memeliki keuletan yang cukup. Pada penelitian ini sudah dihasilkan target sesuai dengan RSNI untuk dodos.

\section{SARAN}

Analisis RSM (Respon Surface Method) sangat dianjurkan untuk melakukan penelitian selanjutnya, sehingga akan diketahui secara tepat faktor yang paling berpengaruh dari temperatur,waktu penahanan dan komposisi pack carburizing.

Variasi jenis arang lain untuk diketahui jenis arang apa yang akan memberikan pengaruh pengerasan permukaan yang lebih tinggi

\section{DAFTAR PUSTAKA}

Mujiyono Mujiyono, \& Arianto Leman Sumowidagdo. (2008). Meningkatkan Pengaruh Karburisasi Padat pada Baja Karbon Rendah dengan Optimasi Ukuran Serbuk Arang Tempurung Kelapa. Jurnal Teknik Mesin, 10(1), 8-14.

Journal "PENGARUH SUHU CARBURIZING MENGGUNAKAN MEDIA ARANG BATOK KELAPA TERHADAP KEKERASAN DAN KETAHANAN AUS RODA GIGI BAJA AISI 4140",Skripsi S-1 Ahmad Aniq Sofiyyudin , Fakultas Teknik Universitas Negeri Semarang.

Setiamarga, Budi Hartono, Fahrudin, Ely, Rumendi, Umen; Karburisasi padat dengan media arang batok pada baja karbon rendah untuk dies dan punch proses stamping profil lingkaran, Jakarta PDII-LIPI, 2005.

Mulyadi, Eka Sanitra, Kajian Perubahan Kekerasan \& Difusi Karbon Sebagai Akibat Dari Proses Karburisasi Dan Proses Kuancing Pada Material Gigi Perontok Power Thresher,Jurnal Teknik Mesin, Vol.7, N0.1 Juni 2010, ISSN 18298958.

Brandt, Daniel A. \& Warner, J.C., Metallurgy Fundamentals, p. 171, Amerika, Goodheart-Wilcox Company, Inc, 2005.

Fransisco, Rosario, Indonesia Produsen terbesar Minyak Kelapa Sawit, www.tempo.com, Bandung, Indonesia, November 2013.

Departemen Perindustrian Indonesia, Gambaran Sekilas Minyak Kelapa Sawit, hal. 4, Sektretarian Jenderal, Pusat Data dan Informasi, Jakarta, Indonesia. 2007.

Suherman, Perbaikan Sifat Fisis dan Mekanis Alat Panen Buah Kelapa Sawit (Egrek dan Dodos) Produk Lokal, Jurnal Dinamis volume 1 nomor 11, Universitas Sumatera Utara, Indonesia. et al, 2012.

Effendi, Sairul, Pengaruh Perbedaan Waktu Penahanan Suhu Stabil terhadap Kekerasan Logam, Indonesia, 10 Jurnal Austenit, Teknik Mesin Politeknik Negeri Sriwijawa, 2009.

ASM Handbook volume 1, Properties and Selection: Irons, Steels and High Performance Alloys Section, ASM International, Amerika, 2005.

ASM Handbook volume 9, Metallography and Microstructures, ASM International, 
Amerika, 2004.

Suyanto, Irham, Pengaruh Tipe Pengerasan terhadap Distribusi Kekerasan, Kedalam Difusi dan Struktur Mikro Baja Karbon Rendah (Mild Steel) yang Telah Dikarburisasi, Surabaya, Indonesia, Jurnal Ilmiah Semesta Teknika, Volume 46 Nomor 1 Tahun, 2007.

Mizhar, Susri dan Suherman, Pengaruh Perbedaan Kondisi Tempering terhadap Struktur Mikro dan Kekerasan dari Baja AISI 4140, Medan, Indonesia, Jurnal Dinamis Volume II Nomor 8 Januari 2011. 